\title{
A Voltage-Independent Calcium Current Inhibitory Pathway Activated by Muscarinic Agonists in Rat Sympathetic Neurons Requires Both $G \alpha_{\mathrm{q} / 11}$ and $\mathrm{G} \beta \gamma$
}

\author{
Paul J. Kammermeier, Victor Ruiz-Velasco, and Stephen R. Ikeda \\ Laboratory of Molecular Physiology, Guthrie Research Institute, Sayre, Pennsylvania 18840
}

\begin{abstract}
Calcium current modulation by the muscarinic cholinergic agonist oxotremorine methiodide (oxo-M) was examined in sympathetic neurons from the superior cervical ganglion of the rat. Oxo-M strongly inhibited calcium currents via voltage-dependent (VD) and voltage-independent (VI) pathways. These pathways could be separated with the use of the specific $M_{1}$ acetylcholine receptor antagonist $M_{1}$-toxin and with pertussis toxin (PTX) treatment. Expression by nuclear cDNA injection of the regulator of G-protein signaling (RGS2) or a phospholipase $\mathrm{C} \beta 1 \mathrm{C}$-terminal construct (PLC $\beta$-ct) selectively reduced $\mathrm{VI}$ oxo-M modulation in PTX-treated and untreated cells. Expression of the $\mathrm{G} \beta \gamma$ buffers transducin $\left(\mathrm{G} \alpha_{\mathrm{tr}}\right)$ and a G-protein-coupled-receptor kinase
\end{abstract}

(GRK3) construct (MAS-GRK3) eliminated oxo-M modulation. Activation of the heterologously expressed neurokinin type 1 receptor, a $\mathrm{G} \alpha_{\mathrm{q} / 11}$-coupled receptor, resulted in VI calcium current modulation. This modulation was eliminated with coexpression of $\mathrm{G} \alpha_{\mathrm{tr}}$ or MAS-GRK3. Cells expressing $\mathrm{G} \beta_{1} \gamma_{2}$ were tonically inhibited via the VD pathway. Application of oxo-M to these cells produced $\mathrm{VI}$ modulation and reduced the amount of current inhibited via the VD pathway. Together, these results confirm the requirement for $\mathrm{G} \beta \gamma$ in VD modulation and implicate $\mathrm{G} \alpha_{\mathrm{q}}$-GTP and $\mathrm{G} \beta \gamma$ as components in the potentially novel VI pathway.

Key words: N-type calcium channel; ion channel modulation; voltage dependent; sympathetic neurons; SCG; G-protein
Calcium current modulation by G-protein-coupled receptors can proceed through many pathways. A well studied and widespread mechanism in neurons is the voltage-dependent (VD) inhibition seen in many systems (Hille, 1994). This modulation is initiated by G-protein activation and mediated by the G-protein $\beta \gamma$ subunit (Herlitze et al., 1996; Ikeda, 1996). G $\beta \gamma$ appears to directly interact with N- and P/Q-type calcium channels (Zhang et al., 1996; DeWaard et al., 1997; Page et al., 1997; Zamponi et al., 1997), causing a shift in channel gating that results in smaller currents with slower activation kinetics at moderate voltages (Bean, 1989; Elmslie et al., 1990). When membrane potential is driven to positive voltages, this shift can be at least partially reversed, resulting in "facilitated" (relieved of inhibition) currents. Therefore, kinetic slowing and facilitation can be used to identify this mechanism. Conversely, other modulatory pathways inhibit calcium channels by mechanisms insensitive to membrane potential. These forms of inhibition are collectively referred to as voltage independent (VI) and are often initiated by activation of PTX-insensitive G-proteins (Hille, 1994).

Because of the expression of multiple muscarinic acetylcholine receptor (mAchR) subtypes in superior cervical ganglion (SCG) neurons, application of a nonspecific muscarinic agonist initiates multiple modulatory pathways. The resulting calcium current inhibition has both VD and VI components. Activation of $\mathrm{M}_{4}$ (Bernheim et al., 1992) mAchRs, which couple to $G_{i / o}$ G-proteins, produces a VD, PTX-sensitive calcium current inhibition (Bernheim et al., 1992; Delmas et al., 1998a,b). This inhibition is mediated by the well defined pathway described above. Activation of $\mathrm{M}_{1}$ mAchRs, which couple to $\mathrm{G}_{\mathrm{q} / 11} \mathrm{G}$-proteins, can produce a calcium current inhibition that is insensitive to PTX and membrane poten-

Received Feb. 24, 2000; revised May 5, 2000; accepted May 11, 2000.

This work was supported by National Institutes of Health Grants GM56180 and NS37615 (S.R.I.) and NS10943 (P.J.K.). We thank Marina King for valuable technical assistance and Dr. Seong-Woo Jeong for helpful critique of this work. We also thank M. I. Simon, R. J. Lefkowitz, D. R. Forsdyke, J. E. Krause, and S. G. Rhee for generously providing plasmids.

Correspondence should be addressed to Stephen R. Ikeda, Guthrie Research Institute, Guthrie Foundation for Education and Research, One Guthrie Square, Sayre, PA 18840. E-mail: sikeda@inet.guthrie.org.

Copyright (C) 2000 Society for Neuroscience $0270-6474 / 00 / 205623-07 \$ 15.00 / 0$ tial. This inhibition appears to have at least two components (Beech et al., 1992). The first, termed "sman" (Beech et al., 1992), has a slow onset, may use a diffusible second messenger because it does not appear to be membrane-delimited, and is sensitive to calcium buffering in rat (Bernheim et al., 1992) but not mouse SCG (Shapiro et al., 1999). The second, termed "fan," is faster in onset and insensitive to calcium buffering (Beech et al., 1992; Delmas et al., 1998a,b). These pathways may be used by other receptors, such as the angiotensin II and substance P (SP) receptors (Shapiro and Hille, 1993; Shapiro et al., 1994). Although some characterization of these pathways has been completed, the underlying mechanisms have not been precisely defined. In addition, experimental conditions (e.g., calcium buffering levels) may influence whether these pathways are observed.

Experiments described in this study were designed to examine the mechanisms of calcium current modulation via natively expressed mAchRs, with emphasis on the observed VI inhibitory pathway. This pathway differed from the voltage-independent inhibitory sman pathway described above (Beech et al., 1992; Bernheim et al., 1992; Delmas et al., 1998a,b). The experiments described below will show that the VI and VD pathways can be separated and begin to elucidate the mechanism of the potentially novel VI pathway.

\section{MATERIALS AND METHODS}

Cell isolation, cDNA injection, and plasmids. A detailed description of the isolation and cDNA injection procedure is available elsewhere (Ikeda, 1997). The methods used were approved by the Institutional Animal Care and Use Committee. Briefly, the SCG were removed from adult Wistar rats (175-225 gm) after decapitation and incubated in Earle's balanced salt solution (Life Technologies, Rockville, MD) containing $0.4 \mathrm{mg} / \mathrm{ml}$ trypsin (Worthington Biochemicals, Freehold, NJ), $0.6 \mathrm{mg} / \mathrm{ml}$ collagenase D (Boehringer Mannheim, Indianapolis, IN) and $0.05 \mathrm{mg} / \mathrm{ml}$ DNase I (Sig$\mathrm{ma}$, St. Louis, MO) for $1 \mathrm{hr}$ at $35^{\circ} \mathrm{C}$. Cells were then centrifuged $(50 \times \mathrm{g})$, transferred to minimum essential medium (Fisher Scientific, Pittsburgh, PA), plated on poly-L-lysine-coated $35 \mathrm{~mm}$ polystyrene tissue culture dishes, and placed in an incubator (95\% air and $5 \% \mathrm{CO}_{2} ; 100 \%$ humidity) at $37^{\circ} \mathrm{C}$ before DNA injection. After injection, cells were incubated overnight at $37^{\circ} \mathrm{C}$, and patch-clamp experiments were performed the following day. Where indicated, neurons were incubated overnight with PTX $(0.5$ $\mu \mathrm{g} / \mathrm{ml}$; List Biological, Campbell, CA) in the culture media. 
Injection of cDNA was performed with an Eppendorf 5246 microinjector and 5171 micromanipulator (Eppendorf, Madison, WI) 4-6 hr after cell isolation. Plasmids were stored at $-20^{\circ} \mathrm{C}$ as a $1 \mu \mathrm{g} / \mu \mathrm{l}$ stock solution in TE buffer (10 mm Tris, $1 \mathrm{~mm}$ EDTA, pH 8). Transducin was injected at 0.1 $\mu \mathrm{g} / \mu \mathrm{l}$ (in pcDNA3.1-; Invitrogen, Carlsbad, CA). RGS2 (pCI; Promega, Madison, WI), PLC- $\beta$-ct (pEGFP-C1; Clontech, Palo Alto CA), and MAS-GRK3 (pcDNA3.1+; Invitrogen) were injected at $0.1,0.1$, and 0.01 $\mu \mathrm{g} / \mu \mathrm{l}$, respectively. Detailed descriptions of these constructs are available in Kammermeier and Ikeda (1999). Type 1 neurokinin receptor $\left(\mathrm{NK}_{1}\right)$ (pCI; original plasmid from J. E. Krause, Neurogen Corporation) was injected at the concentrations noted in the text. $\mathrm{G} \beta_{1}$ and $\mathrm{G} \gamma_{2}$ plasmids (pCI) were injected at $0.05 \mu \mathrm{g} / \mu \mathrm{l}$. Neurons were coinjected with "enhanced" green fluorescent protein (GFP) cDNA $(0.005 \mu \mathrm{g} / \mu \mathrm{l})$ (pEGFP$\mathrm{N} 1$; Clontech) to facilitate later identification of successfully injected cells.

All inserts were sequenced using an automated DNA sequencer (ABI 310, PE Applied Biosystems, Foster City, CA). PCR products were purified with silica membrane spin columns (Qiagen, Valencia, CA) before restriction digestion and ligation. Plasmids were propagated in XL1-blue bacteria (Stratagene, La Jolla, CA), and minipreps were prepared using Qiagen anion exchange columns.

Electrophysiology and data analysis. Patch pipettes were made from 7052 glass (Garner Glass, Claremont, CA) and had resistances of 1-4 $\mathrm{M} \Omega$. Series resistances were 2-7 M $\Omega$ before electronic compensation, which was typically $80 \%$. Ruptured-patch whole-cell recordings were made using an Axopatch 200 or $200 \mathrm{~A}$ patch clamp amplifier (Axon Instruments, Foster City, CA). Voltage protocol generation and data acquisition were performed using custom software on a Macintosh Quadra series computer (Apple Computer, Cupertino, CA) with a MacADIOS II data acquisition board (G.W. Instruments, Somerville, MA). Currents were low-passfiltered at $5 \mathrm{kHz}$ using the four-pole Bessel filter in the patch-clamp amplifier, digitized at $2-5 \mathrm{kHz}$, and stored on the computer for later analysis. Experiments were performed at $21-24^{\circ} \mathrm{C}$ (room temperature). Data analysis was performed using Igor software (Wavemetrics, Lake Oswego, OR).

The external (bath) solution contained (in $\mathrm{mm}$ ): 155 Tris hydroxymethyl aminomethane, $20 \mathrm{HEPES}, 10$ glucose, $10 \mathrm{CaCl}_{2}$, and 0.0003 tetrodotoxin, $\mathrm{pH} 7.4$, osmolality $320 \mathrm{mOsm} / \mathrm{kg}$. The internal (pipette) solution contained (in mM): $120 \mathrm{~N}$-methyl-D-glucamine (NMG) methanesulfonate, $20 \mathrm{TEA}$ 11 EGTA, 10 HEPES, 10 sucrose, $1 \mathrm{CaCl}_{2}, 4 \mathrm{MgATP}, 0.3 \mathrm{Na}_{2} \mathrm{GTP}$, and 14 Tris creatine phosphate, $\mathrm{pH} 7.2$, osmolality $300 \mathrm{mOsm} / \mathrm{kg}$. $\mathrm{M}_{1}$-toxin was obtained from Peptides International (Louisville, KY). Where indicated, external solutions contained $10 \mu \mathrm{M}$ oxotremorine methiodide (oxo-M) or $10 \mu \mathrm{M}$ norepinephrine (NE). All drugs and control solutions were applied to cells using a custom, gravity-driven perfusion system positioned $\sim 100$ $\mu \mathrm{m}$ from the cell, which allowed rapid solution exchange $(250 \mathrm{msec})$. $\mathrm{M}_{1}$-toxin application via the perfusion system was begun before seal formation and was maintained for the duration of the experiment. Solutions containing the $\mathrm{M}_{1}$-toxin $(30-100 \mathrm{nM})$ also contained $0.1 \mathrm{mg} / \mathrm{ml}$ cytochrome $c$. U73122 (Sigma) was dissolved in dimethylsulfoxide and applied to cells $\sim 30$ min before appropriate experiments. Percentage inhibition of muscarinic responses was calculated as the decrease in current of the third sweep in oxo-M $(\sim 30 \mathrm{sec}$, to allow steady state to be reached $)$ compared with the last sweep before application of the drug. For NE responses, inhibition was calculated from the maximal inhibition in the drug.

\section{RESULTS}

\section{Calcium current inhibition by oxotremorine-M}

The voltage protocol illustrated in Figure $1 A$ was run every $10 \mathrm{sec}$ from a holding potential of $-80 \mathrm{mV}$. This protocol (Elmslie et al., 1990) consists of a test pulse to $+10 \mathrm{mV}$ (the "prepulse") followed by a strong depolarizing step to $+80 \mathrm{mV}$, a brief return to $-80 \mathrm{mV}$, and finally another test pulse to $+10 \mathrm{mV}$ (the "postpulse"), during which currents inhibited by the VD pathway will be facilitated. Application of both $10 \mu \mathrm{M}$ oxo-M and $10 \mu \mathrm{M}$ NE potently inhibited the calcium current in the prepulse, whereas inhibition by $\mathrm{NE}$ was much less potent in the postpulse (Fig. $1 A$ ), indicating that $\mathrm{NE}$ modulation was predominantly $\mathrm{VD}$. The total oxo-M inhibition, in contrast, had a large VI component (Fig. $1 A, C$ ). However, a VD component of oxo-M inhibition was apparent because postpulse currents were facilitated and kinetic slowing was routinely observed in the prepulse currents (Fig. 1A). Although the NE modulation was not completely reversed by the depolarizing pulse, it was considered representative of the $G \beta \gamma$-mediated, VD pathway because it was PTX sensitive and nearly completely blocked by G $\beta \gamma$ buffers (Kammermeier and Ikeda, 1999). Thus, the degree of voltage dependence of $\mathrm{NE}$ inhibition was taken as an arbitrary standard of VD inhibition. The effect of oxo-M was rapid, generally reaching steady state in 20-30 $\mathrm{sec}$ (Fig. $1 C$ ). Figure $1 B$ illustrates
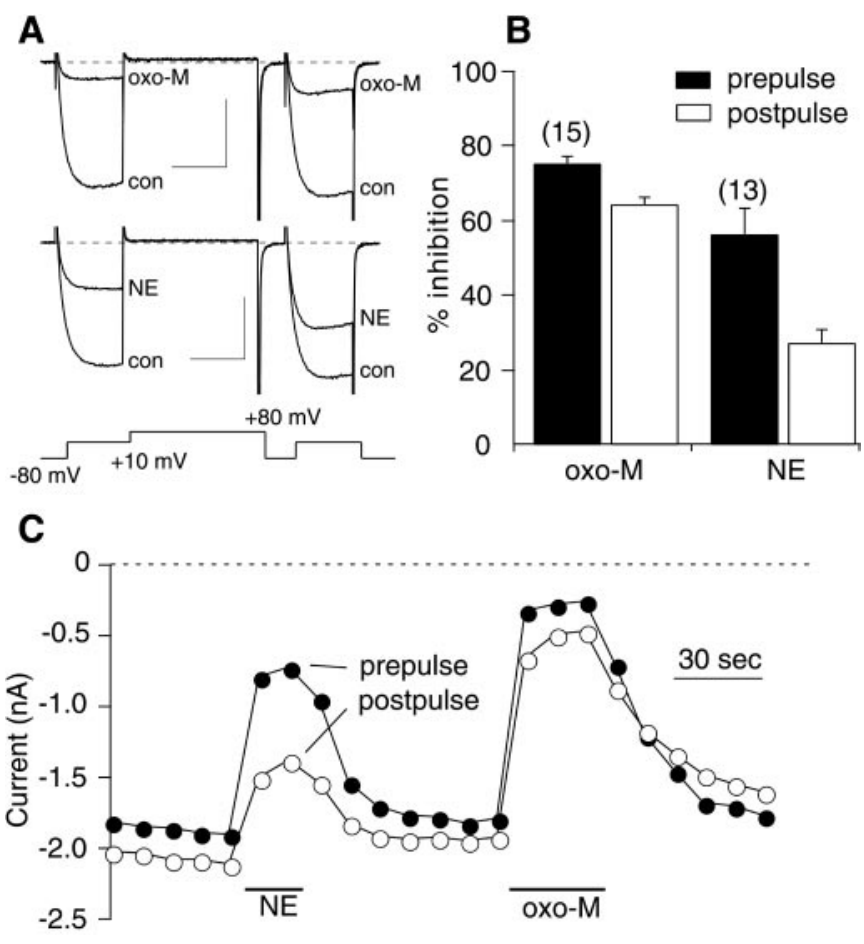

Figure 1. Oxo-M inhibits calcium currents in SCG neurons. A, Sample current traces illustrating control (con: before drug application) and inhibited currents (oxo-M or $N E$ : in the presence of the drug). The holding potential for all experiments was $-80 \mathrm{mV}$. The voltage protocol, shown below the current traces, was repeated at $10 \mathrm{sec}$ intervals. Calibration: $1 \mathrm{nA}$, 20 msec. $B$, Bar graph indicating average (+SEM) prepulse inhibition (first test pulse to $+10 \mathrm{mV}$ in the illustrated voltage protocol: solid bars) and postpulse inhibition (second test pulse to $+10 \mathrm{mV}$ : open bars) by $10 \mu \mathrm{M}$ oxo-M and $10 \mu \mathrm{M}$ NE. Numbers of cells for each drug are shown in parentheses. $C$, Time course for cell shown in $A$. Filled circles represent current measurements from the prepulse; open circles are from the postpulse. Measurements are taken $10 \mathrm{msec}$ from the beginning of each step.

the average inhibition $(+\mathrm{SEM})$ of the prepulse and postpulse currents produced by application of $10 \mu \mathrm{M}$ oxo-M and $10 \mu \mathrm{M} \mathrm{NE}$. Prepulse (filled bars) and postpulse (open bars) inhibition by oxo-M was $76 \pm 3$ and $64 \pm 3 \%(n=15)$. NE inhibited the prepulse and postpulse currents by $56 \pm 7$ and $27 \pm 4 \%(n=13)$, respectively. $\mathrm{N}$-type calcium channels were assumed to be the predominant channel modulated by oxo-M. In SCG neurons recorded under these conditions, N-type current makes up the vast majority of the total calcium current, and the contribution of L-type channels (which can be modulated by $\mathrm{G} \alpha_{\mathrm{q} / 11}$ activation in other systems) is negligible (Zhu and Ikeda, 1994).

\section{VD and VI pathways can be separated using PTX and M1-toxin}

To examine which $\mathrm{mAchRs}$ were responsible for each inhibitory pathway, calcium current modulation was examined in the presence of $\mathbf{M}_{1}$-toxin, a selective $\mathrm{M}_{1} \mathrm{mAchR}$ antagonist (Max et al., 1993). Application of $10 \mu \mathrm{M}$ oxo-M to SCG neurons in the continuous presence of 30-100 nM $\mathrm{M}_{1}$-toxin produced predominantly VD inhibition of the calcium currents as evidenced by kinetic slowing and prepulse facilitation (Fig. $2 A$, top). Interestingly, the magnitude of total inhibition in the prepulse was similar to that of cells in the absence of $\mathrm{M}_{1}$-toxin. However, the facilitation ratio (postpulse current/prepulse current) of oxo-M-inhibited currents in the presence of $\mathrm{M}_{1}$-toxin was $3.4 \pm 0.2$, compared with $1.9 \pm 0.1$ in control cells. In the presence of $\mathrm{M}_{1}$-toxin, the average inhibition by oxo-M in the prepulse and postpulse was $70 \pm 6$ and $36 \pm 5 \%(n=9)$, respectively (Fig. $2 B$ ). These data confirm that activation of $\mathbf{M}_{1}$ $\mathrm{mAchRs}$ is involved in VI inhibition and suggest that $\mathrm{M}_{1}$-toxin is an effective $M_{1} m A c h R$ antagonist. 
A
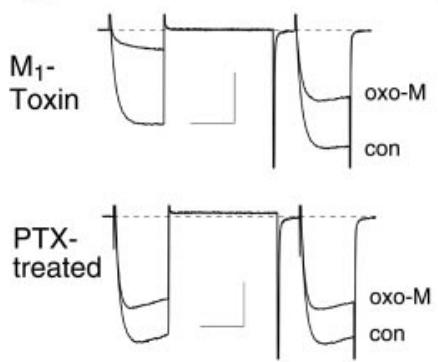

B

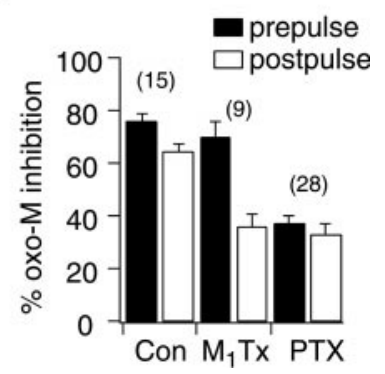

A
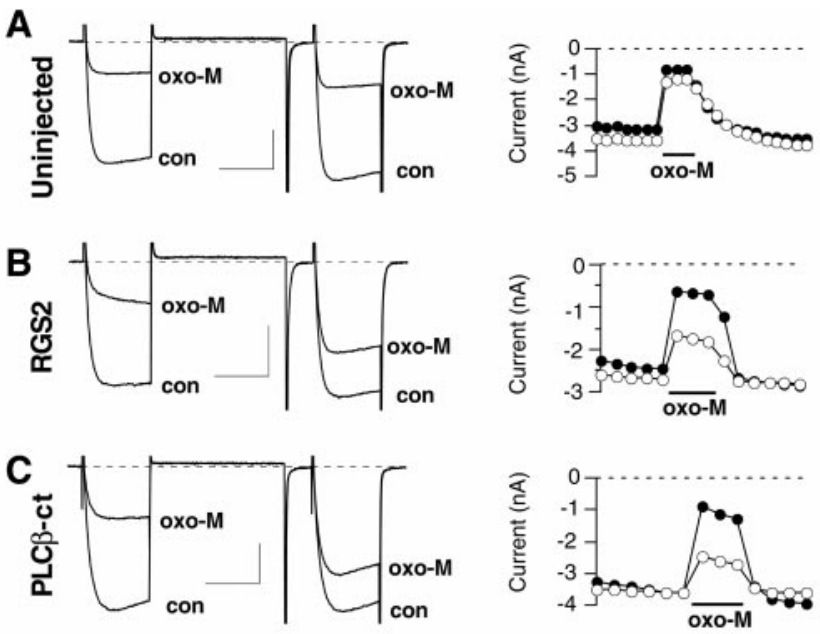

D
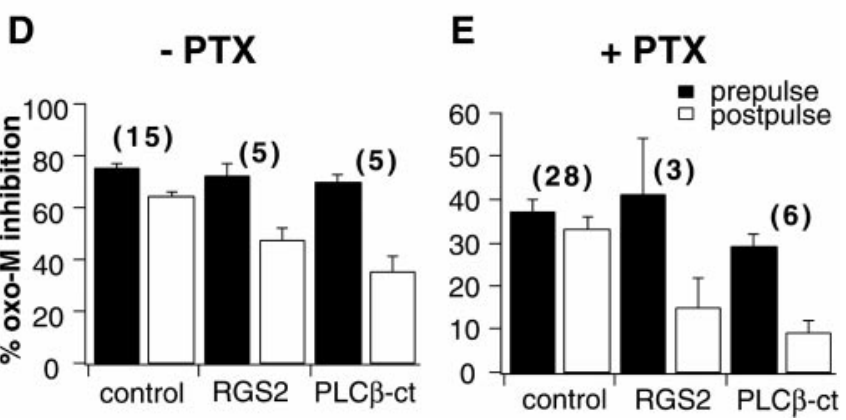

Figure 3. Expression of RGS2 or PLC $\beta$-ct reduces VI modulation. $A-C$, Sample current traces (left) and corresponding time courses (right) for uninjected cells and cells expressing RGS2 or PLC $\beta$-ct, respectively. The voltage protocol is the same as in Figure $1 A$. Calibration: $1 \mathrm{nA}, 20 \mathrm{msec}$ for all current traces. $D, E$, Bar graphs indicating average ( + SEM) prepulse (filled bars) and postpulse (open bars) inhibition for uninjected (control) cells and cells expressing RGS2 and PLC $\beta$-ct for untreated cells $(D)$ and cells treated with $0.5 \mu \mathrm{g} / \mathrm{ml}$ PTX $(E)$.

\section{Expression of RGS2 and PLC $\beta$-ct selectively reduces VI oxo-M inhibition}

To test whether oxo-M-mediated, VI calcium current inhibition proceeds through a $\mathrm{G} \alpha_{\mathrm{q} / 11}$-mediated pathway, calcium current inhibition was examined in the presence of RGS2 and a GFPtagged, C-terminal construct of phospholipase $\mathrm{C} \beta 1$ (PLC $\beta$-ct) (Kammermeier and Ikeda, 1999). Both of these constructs can selectively bind $\mathrm{G} \alpha_{\mathrm{q} / 11}$-GTP (Wu et al., 1993; Heximer et al., 1997). In contrast to uninjected cells (Fig. $3 A$ ), cells expressing RGS2 or PLC $\beta$-ct exhibited predominantly VD inhibition on exposure to oxo-M (Fig. $3 B, C$ ). Under these conditions, prepulse inhibition was similar to control cells, but postpulse inhibition was reduced to $47 \pm 5 \%$ in cells expressing $\operatorname{RGS} 2(n=5)$ and $35 \pm 6 \%$ in cells expressing PLC $\beta$-ct $(n=5)$ (Fig. $3 D)$.

This effect was also apparent when the VI pathway was examined in isolation. Figure $3 E$ illustrates averaged data from PTX-treated, uninjected cells (Fig. 3E, control) and those expressing either RGS2 or PLC $\beta$-ct. The average prepulse and postpulse inhibition for these groups was $37 \pm 3$ and $33 \pm 3 \%$ for uninjected cells $(n=$ 28), $41 \pm 13$ and $15 \pm 8 \%$ for RGS2-expressing cells $(n=3)$, and $29 \pm 3$ and $9 \pm 3 \%$ for PLC $\beta$-ct-expressing cells $(n=6)$ after overnight PTX treatment. Therefore, the VI inhibition that was exhibited in PTX-treated cells appeared to be converted to VD inhibition when $\mathrm{G} \alpha_{\mathrm{q} / 11}-\mathrm{GTP}$ was buffered. Apparently, the $\mathrm{G} \beta \gamma$ that mediated the VD inhibition in this experiment was released on $\mathrm{G} \alpha_{\mathrm{q} / 11}$ activation, indicating that $\mathrm{G} \beta \gamma$ from either $\mathrm{G}_{\mathrm{i} / \mathrm{o}}$ or $\mathrm{G} \alpha_{\mathrm{q} / 11}$ has the ability to produce VD inhibition under certain circumstances. Together, these data indicate that the VI component of oxo-M modulation requires $\mathrm{G} \alpha_{\mathrm{q} / 11}-\mathrm{GTP}$. However, activation of phospholipase $\mathrm{C}$ did not appear to be involved in this pathway, because the phospholipase C inhibitor U73122 had no effect on calcium current modulation by oxo-M in PTX-treated cells (data not shown).

\section{Buffers of $\mathbf{G} \boldsymbol{\beta} \gamma$ block inhibition by oxo-M}

Because VD inhibition is mediated by $\mathrm{G} \beta \gamma$, and VI inhibition appears to require $\mathrm{G} \alpha_{\mathrm{q} / 11}$-GTP, oxo-M modulation was examined in cells expressing proteins that bind $\mathrm{G} \beta \gamma$. When transducin, a $\mathrm{G} \alpha$ subunit from retina $\left(\mathrm{G} \alpha_{\mathrm{tr}}\right)$, or a membrane-associating $\mathrm{C}$-terminal GRK3), two G $\beta \gamma$-binding proteins, were expressed in SCG neurons, the total oxo-M inhibition was nearly eliminated (Fig. 4A). Prepulse and postpulse oxo-M inhibition of $\mathrm{G} \alpha_{\mathrm{tr}}$-expressing cells was $11 \pm 5$ and $13 \pm 4 \%$, respectively $(n=8)$. In MAS-GRK3expressing cells, prepulse and postpulse inhibition was $7 \pm 3$ and $11 \pm 4 \%$, respectively $(n=9)$ (Fig. $4 B$ ). Finally, this experiment was repeated in cells pretreated with PTX. The predominantly VI modulation normally seen in these cells was eliminated by expression of $\mathrm{G} \alpha_{\mathrm{tr}}$ or MAS-GRK3 (Fig. 4C). PTX-treated cells expressing $\mathrm{G} \alpha_{\mathrm{tr}}$ had prepulse and postpulse inhibition of $6 \pm 2$ and $11 \pm$ $2 \%$, respectively $(n=17)$. Prepulse and postpulse inhibition in MAS-GRK3-expressing cells was $-2 \pm 2$ and $6 \pm 3 \%$, respectively $(n=16)$ (Fig. $4 D)$. It seems unlikely that the effects of $\mathrm{G} \beta \gamma$ buffers on oxo-M modulation resulted from nonspecific actions because neither of these agents altered oxo-M-mediated M-type potassium current modulation. M-current was inhibited $77 \pm 1 \%$ in control cells, $84 \pm 7 \%$ in $\mathrm{G} \alpha_{\mathrm{tr}}$-expressing cells, and $77 \pm 6 \%$ in MASGRK3-expressing cells; $n=3$ for each group. These data confirm that both the VD and VI pathways require G $\beta \gamma$. It should be noted that in early attempts in this study, this experiment appeared to construct of a G-protein-coupled receptor kinase (termed MAS- 
A
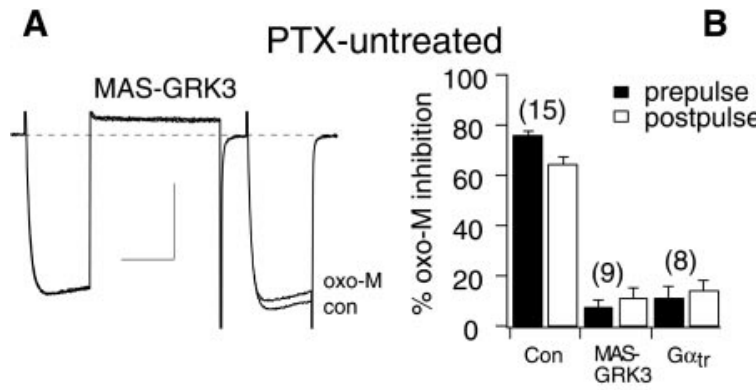

C

PTX-treated
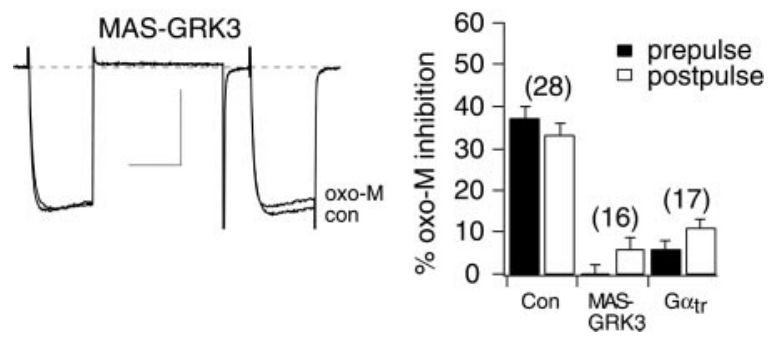

Figure 4. Expression of MAS-GRK3 or $\mathrm{G} \alpha_{\mathrm{tr}}$ eliminates oxo-M modulation. $A$, Sample current traces illustrating currents before (con) and during oxo-M application (oxo- $M$ ) in a MAS-GRK3-expressing cell. $B$, Bar graph depicting average $(+\mathrm{SEM})$ prepulse and postpulse inhibition of calcium currents in uninjected cells and cells expressing MAS-GRK3 or G $\alpha_{\mathrm{tr}} . C$, $D$, Same as $A$ and $B$, but for cells pretreated overnight with $0.5 \mu \mathrm{g} / \mathrm{ml}$ PTX. Calibration: $1 \mathrm{nA}, 20 \mathrm{msec}$. The voltage protocol is the same as in Figure $1 A$.

produce selective elimination of the VD pathway in PTXuntreated cells. The apparent VI inhibition that remained was determined to have resulted from inefficient $\mathrm{G} \alpha_{\mathrm{tr}}$ and MAS-GRK3 expression or inefficient buffering attributable to the large amount of $\mathrm{G} \beta \gamma$ released on oxo-M application. To circumvent this problem, NE-induced inhibition was used as a paired positive control for expression of the $\mathrm{G} \beta \gamma$ buffers. Only cells exhibiting $<15 \%$ inhibition by $\mathrm{NE}$ were included in the final analysis shown in Figure 4, $A$ and $B$.

\section{Neurokinin type 1 receptor-mediated VI inhibition is inhibited by $\mathbf{G} \boldsymbol{\beta} \boldsymbol{\gamma}$ buffering}

The experiments above indicate that oxo-M-mediated VI calcium current inhibition requires $\mathrm{G} \beta \gamma$ in addition to $\mathrm{G} \alpha_{\mathrm{q} / 11}-\mathrm{GTP}$. To test the generality of these effects, modulation of the calcium current was examined after activation of an independent $\mathrm{G}_{\mathrm{q} / 11}$-coupled receptor. For this experiment, $\mathrm{NK}_{1}$ was chosen. cDNA encoding $\mathrm{NK}_{1}$ was injected at several concentrations ranging from 0.006 to $120 \mathrm{ng} / \mu \mathrm{l}$ to determine an optimal level for $\mathrm{NK}_{1}$ expression (Fig. $5 A$ ). SP was used as the $\mathrm{NK}_{1}$ agonist (Krause et al., 1994). After nuclear injection of $6 \mathrm{ng} / \mu \mathrm{l} \mathrm{NK} \mathrm{K}_{1} \mathrm{cDNA}$, maximal calcium current inhibition was obtained. Concentrations below $0.6 \mathrm{ng} / \mu \mathrm{l}$ produced no detectable changes in calcium current amplitude (but see Shapiro and Hille, 1993). Subsequent experiments were therefore performed after injection of $6 \mathrm{ng} / \mu \mathrm{l} \mathrm{NK} \mathrm{NK}_{1}$ cDNA. In addition, experiments with $\mathrm{NK}_{1}$ were performed using $\alpha$-neurokinin $(\alpha-\mathrm{NK})$ as the $\mathrm{NK}_{1}$ agonist, because the action of $\alpha$-NK was more readily reversible than that of SP (data not shown).

Application of $1 \mu \mathrm{M} \alpha$-NK to cells expressing $\mathrm{NK}_{1}$ produced a VI calcium current inhibition in which little kinetic slowing or prepulse facilitation was observed (Fig. 5B, top). $\alpha$-NK produced inhibition of $48 \pm 6 \%$ in the prepulse and $41 \pm 4 \%$ in the postpulse in control $\mathrm{NK}_{1}$-expressing cells. Cells expressing $\mathrm{G} \alpha_{\mathrm{tr}}$ in addition to $\mathrm{NK}_{1}$ exhibited little calcium current inhibition on exposure to 1 $\mu \mathrm{M} \alpha$-NK (Fig. 5B, bottom). Prepulse and postpulse inhibition in these cells were $3 \pm 2$ and $10 \pm 3 \%$, respectively $(n=10)$ (Fig. $5 C)$. This result indicates that the VI inhibition mediated by $\mathrm{NK}_{1}$ is sensitive to $\mathrm{G} \alpha_{\mathrm{tr}}$ and thus requires activated $\mathrm{G} \beta \gamma$. Therefore, the
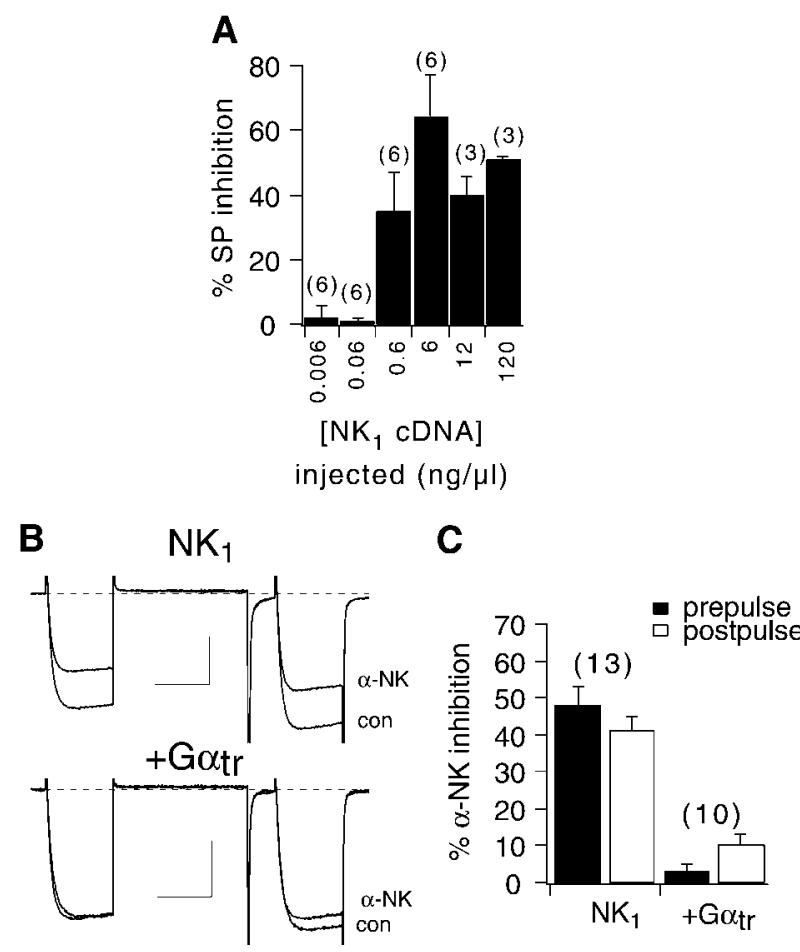

Figure 5. $\alpha$-NK application to $\mathrm{NK}_{1}$-expressing cells produces a $\mathrm{G} \alpha \mathrm{tr}_{\mathrm{tr}}$ sensitive, VI inhibition. $A$, Bar graph indicating the average ( $+\mathrm{SEM})$ maximal calcium current inhibition by $1 \mu \mathrm{M}$ SP (in the prepulse) in cells after nuclear injection of the indicated concentration of $\mathrm{NK}_{1}$ cDNA (see Materials and Methods for description of injection procedure). B, Sample current traces illustrating $1 \mu \mathrm{M} \alpha$-NK inhibition in cells expressing $\mathrm{NK}_{1}$ alone (top) or with $\mathrm{G} \alpha_{\mathrm{tr}}$ (bottom). Calibration: B, top, $1 \mathrm{nA}, 20 \mathrm{msec} ; B$, bottom, $0.5 \mathrm{nA}, 20 \mathrm{msec}$. $C$, Bar graph depicting average prepulse and postpulse inhibition by $1 \mu \mathrm{M} \alpha-\mathrm{NK}$ for $\mathrm{NK}_{1}$-expressing cells (injected with $6 \mathrm{ng} / \mu \mathrm{l} \mathrm{NK_{1 }}$ cDNA).

interpretation that VI inhibition requires $\mathrm{G} \beta \gamma$ is supported. Finally, cells coexpressing $\mathrm{NK}_{1}$ and PLC $\beta$-ct exhibited VD inhibition on $\alpha$-NK application (data not shown). In these cells, prepulse inhibition was $24 \pm 3 \%$ and postpulse inhibition was $4 \pm 2 \%(n=$ 4). These data indicate that $\mathrm{NK}_{1}$ activation can activate the same VI pathway as $M_{1} m A c h R$ activation and support the finding that this pathway requires $\mathrm{G} \alpha_{\mathrm{q} / 11}-\mathrm{GTP}$.

\section{Cells expressing $\mathbf{G} \beta \gamma$ exhibit oxo-M inhibition in the postpulse but not prepulse}

The data above indicate that the VI oxo-M-mediated pathway requires not only $\mathrm{G} \alpha_{\mathrm{q} / 11^{-}}$GTP but $\mathrm{G} \beta \gamma$ as well. As a test for independence of the two pathways, oxo-M modulation of calcium current was examined in cells expressing $G \beta_{1} \gamma_{2}$. These cells exhibited strong basal facilitation (basal facilitation ratio $=3.2 \pm 0.3$ ) and kinetic slowing in the prepulse (Fig. $6 A$, con), as expected (Herlitze et al., 1996; Ikeda, 1996). On exposure to oxo-M, the calcium currents were inhibited potently in the postpulse but remained largely unchanged in the prepulse (Fig. $6 B$ ). In addition, oxo-M application resulted in some relief of kinetic slowing in the prepulse (Fig. $6 \mathrm{~A}$, oxo- $M$ ). Oxo-M produced a $5 \pm 7 \%$ inhibition in the prepulse and a $40 \pm 5 \%$ inhibition in the postpulse, which reduced the facilitation ratio to $1.9 \pm 0.2(n=11)$ (Fig. $6 C)$.

Finally, this experiment was repeated in cells treated overnight with PTX (Fig. 6C). In $\mathrm{G} \beta_{1} \gamma_{2}$-expressing cells pretreated with PTX, prepulse inhibition was $2 \pm 6 \%$ and postpulse inhibition was $36 \pm 3 \%$, which reduced the facilitation ratio to $1.9 \pm 0.2(n=9)$ (Fig. 6C), a value indistinguishable from the corresponding value obtained from PTX-untreated cells. These results lend further support to the hypothesis that the VI pathway shares a component with the VD pathway (i.e., G $\beta \gamma$ ). If these two mechanisms operated independently, the prepulse and postpulse currents would be expected to be inhibited similarly in $\mathrm{G} \beta_{1} \gamma_{2}$-expressing cells. There- 

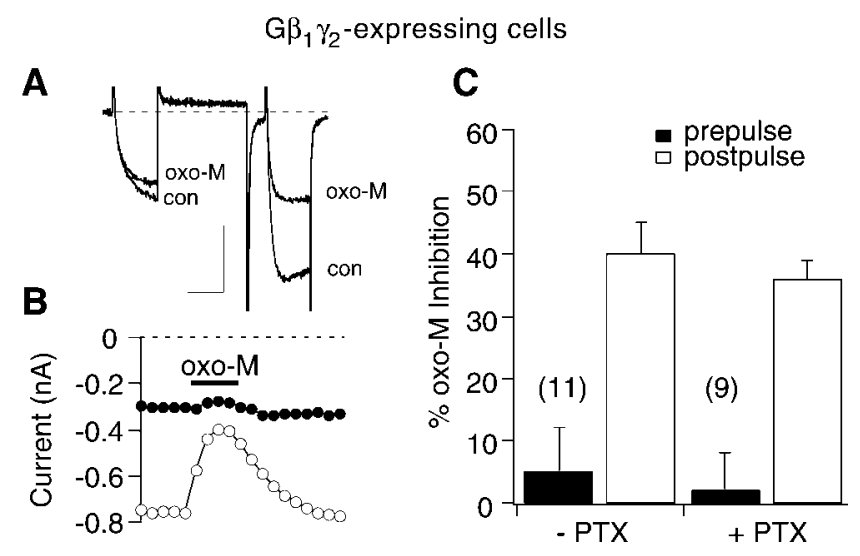

Figure 6. Cells expressing $\mathrm{G} \beta_{1} \gamma_{2}$ exhibit postpulse but not prepulse inhibition on exposure to oxo-M. $A$, Sample current traces illustrating prepulse and postpulse currents before and during application of $10 \mu \mathrm{M}$ oxo-M. Calibration: $0.3 \mathrm{nA}, 20 \mathrm{msec}$. $B$, Time course of oxo-M effect for cell shown in $A$. C, Average (+SEM) oxo-M inhibition in the prepulse ( filled bars) and postpulse (open bars) for untreated cells and cells treated overnight with 0.5 $\mu \mathrm{g} / \mathrm{ml}$ PTX.

fore, these data support the conclusion that $\mathrm{G} \beta \gamma$ (in addition to $\left.\mathrm{G} \alpha_{\mathrm{q} / 11}\right)$ is required for VI inhibition.

\section{DISCUSSION}

This study presents the finding that muscarinic receptor activation can initiate a potentially novel VI calcium current inhibitory pathway that requires $\mathrm{G} \alpha_{\mathrm{q} / 11}-\mathrm{GTP}$ and $\mathrm{G} \beta \gamma$. In addition, evidence has been presented to confirm that in sympathetic neurons from the rat SCG, activation of $\mathrm{mAchRs}$ by oxo-M produces VD and VI calcium current inhibition, mediated by $\mathrm{M}_{4}$ and $\mathrm{M}_{1}$ muscarinic receptors, respectively. Evidence is also presented that suggests that the $\mathrm{VD}$ component is mediated by G-protein $\beta \gamma$ subunits, in agreement with previous studies (Herlitze et al., 1996; Ikeda, 1996).

Previous studies (Beech et al., 1991, 1992; Bernheim et al., 1991, 1992; Delmas et al., 1998a,b) have characterized a VI calcium channel inhibitory pathway in SCG neurons activated by muscarinic receptors, termed sman by Beech et al. (1992). This pathway appeared to require a diff usible intracellular second messenger and was sensitive to high concentrations of intracellular BAPTA (Bernheim et al., 1992). Sman also activated with a much slower time course than the VD inhibition. It is unlikely that the VI pathway observed in the present study corresponds to the sman pathway for the following reasons. First, the present study was conducted with $11 \mathrm{~mm}$ intracellular EGTA. In addition, results obtained with 10 mM BAPTA in the pipette were similar to those reported in this study (data not shown). These levels (10-11 mM) of EGTA or BAPTA would be expected to produce similar calcium buffering as the 20 mM BAPTA used by the Hille and Brown groups (Beech et al., 1991, 1992; Bernheim et al., 1991, 1992; Delmas et al., 1998a,b). Indeed, a gonadotropin-releasing hormone-mediated pathway akin to the sman pathway was shown to be sensitive to $10 \mathrm{~mm}$ EGTA under conditions similar to those presented here (Lewis and Ikeda, 1997). Therefore, with this level of calcium buffering, activation of the sman pathway would be unlikely. Second, the VI inhibition observed in this study appeared to activate somewhat more quickly than sman (Fig. 1). Many factors of this study differed from previous studies that characterized muscarinic, V I calcium current modulation in SCG neurons (Beech et al., 1991; Delmas et al., 1998a), namely the ionic composition of the recording solutions and temperature. Factors such as these may influence which pathways can be activated during whole-cell patch-clamp experiments as well as rates of onset for each pathway. Separate from the sman pathway, another VI component, termed fan, was observed by Beech et al. (1992), which activated more rapidly than sman and was not sensitive to intracellular BAPTA. The VI pathway presented here

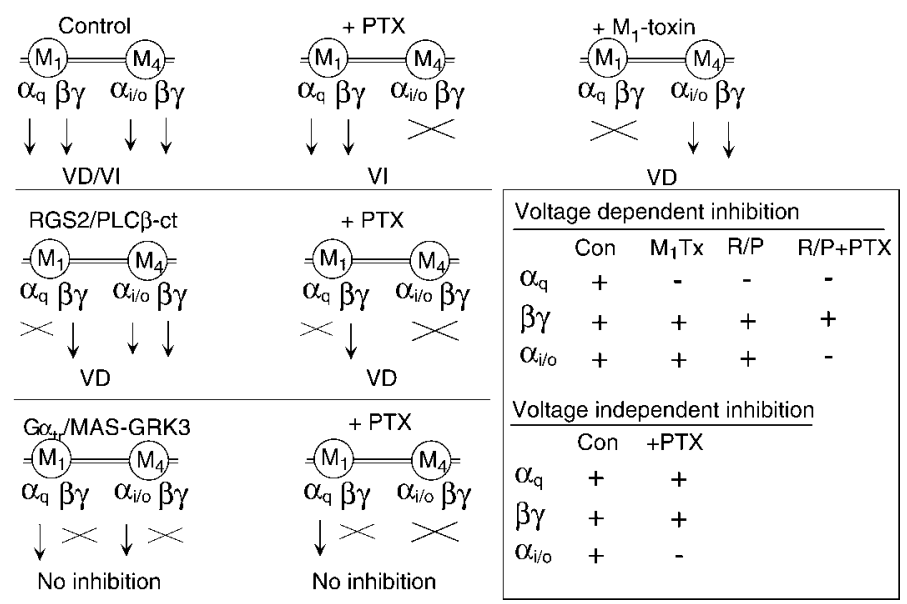

Figure 7. Schematic summary of experiments. Each diagram illustrates the two G-protein-signaling components associated with each receptor $\left(\mathrm{M}_{1}\right.$ or $\mathrm{M}_{4} \mathrm{mAchR}$ ) and the type of modulation observed under each condition (VD, VI, or No inhibition). Arrows indicate that a component is free to be activated and unhindered in its interaction with its effectors. $X$ indicates that a component is unavailable for activation or effector interaction. Note that the smaller, lightened arrow associated with $\mathrm{G} \alpha_{\mathrm{i} / \mathrm{o}}$ indicates only that this component was not found to be involved in either of the pathways of interest in this study and does not imply degree of signal strength. Top row, Schematics for uninjected, untreated cells (Control, first column), uninjected, PTX-treated cells $(+P T X$, second column $)$, and uninjected cells exposed to $\mathrm{M}_{1}$-toxin ( $+M_{1}$-toxin, third column). Center row, Schematics for RGS2 or PLC $\beta$-ct-expressing, untreated cells ( $R G S / P L C b$-ct, first column) and RGS2 or PLC $\beta$-ct-expressing, PTX-treated cells $(+P T X$, second column). Bottom row, Schematics for $\mathrm{G} \alpha_{\mathrm{tr}}$ or MAS-GRK3-expressing, untreated cells $\left(G \alpha_{t r} / M A S-G R K 3\right.$, first column $)$, and for $\mathrm{G} \alpha_{\mathrm{tr}}$ or MAS-GRK3expressing, PTX-treated cells ( + PTX, second column $)$. Inset indicates which one of the components was available $(+)$ or unavailable $(-)$ under each condition in which VD (top) or VI (bottom) inhibition was observed.

may correspond to the fan pathway. However, this pathway was not as well characterized as sman and did not appear to contribute a great deal to the total inhibition, perhaps because of the recording conditions, so direct comparison is difficult. There are other examples of G-protein-coupled receptors producing VD or VI inhibition of N-type calcium current (Hille, 1994). Some receptors, by activating multiple classes of G-proteins, can initiate VD and VI pathways simultaneously (Filippov et al., 1998; Delmas et al., 1999; Kammermeier and Ikeda, 1999). It should also be noted that results from mammalian SCG neurons may differ significantly from those obtained in avian neurons (Diverse-Pierluissi et al., 1997).

The requirement for $\mathrm{G} \beta \gamma$ in the VD pathway has been well established (Herlitze et al., 1996; Ikeda, 1996). However, a recent study (Delmas et al., 1999) has presented evidence that $\mathrm{G}_{\mathrm{o}}-$ and $\mathrm{G}_{\mathrm{i}}$-associated $\beta \gamma$ subunits mediating $\alpha_{2}$-adrenergic calcium current modulation in SCG neurons can produce relatively voltagedependent and voltage-independent inhibition, respectively. Our results indicate that a VI pathway mediated by $\mathrm{M}_{1} \mathrm{mAchRs}$ requires $\mathrm{G} \alpha_{\mathrm{q} / 11^{-}}$GTP in addition to $\mathrm{G} \beta \gamma$. This pathway does not appear to require $G \beta \gamma$ from a specific source. It is unlikely, however, that any component of adrenergic modulation in SCG neurons is akin to the VI, muscarinic pathway in the present study, because of the lack of $\mathrm{G} \alpha_{\mathrm{q} / 11}$ involvement. Under conditions similar to those presented here, RGS2 or PLC $\beta$-ct expression failed to alter the voltage dependence of NE-mediated calcium current inhibition (Kammermeier and Ikeda, 1999).

The strategies of the experiments performed in this study are summarized schematically in Figure 7. Each diagram illustrates the available components (arrows) of the $\mathrm{M}_{1}$ and $\mathrm{M}_{4}$ mAchR signaling pathways under each experimental condition and the type(s) of modulation observed (VD, VI, or both). These experiments were designed to eliminate one or more of these components while the calcium current modulation was observed, thereby allowing identification of the contributing components. Figure 7 (inset) also summarizes the available components under each condition in 
which VD (top) or VI (bottom) modulation was observed. (Note that $\mathrm{G} \beta \gamma$ from either source, $\mathrm{M}_{1}$ or $\mathrm{M}_{4}$, was considered functionally equivalent because each has been shown to produce VD modulation; see Figs. 2, 3E). Under all conditions in which VD modulation was observed, the only component available in every case was $\mathrm{G} \beta \gamma$, confirming that $\mathrm{G} \beta \gamma$ mediates this pathway. In contrast, VI modulation was observed in only two experiments, uninjected control (Fig. 7, top row, first column) and uninjected, PTX-treated (Fig. 7, top row, second column). The common components in these experiments were $\mathrm{G} \alpha_{\mathrm{q}}$ and $\mathrm{G} \beta \gamma$. This indicates that one or both of these components are necessary for the VI pathway. Closer inspection reveals that when either of these components was present in isolation, VI modulation was not observed (Fig. 7, RGS2/PLC $\beta$-ct $+\mathrm{PTX}$, center row, second column, and $\mathrm{G} \alpha_{\mathrm{tr}} / \mathrm{MAS}-\mathrm{GRK} 3+\mathrm{PTX}$, bottom row, second column). This confirms that both $\mathrm{G} \alpha_{\mathrm{q}}$ and $\mathrm{G} \beta \gamma$ are necessary to activate the VI pathway.

Because these separate pathways use a common molecule $(\mathrm{G} \beta \gamma)$, it can be assumed that the inhibition produced by each pathway will not be strictly additive. This fact can explain the apparent discrepancy that arises when each pathway is compared in isolation using $\mathrm{M}_{1}$-toxin or PTX treatment (Fig. 2). Clearly, the inhibition produced in control cells is less than the sum of that produced by each pathway in isolation, at least in the prepulse. However, because little is known about the molecular mechanism of the VI pathway, it is difficult to speculate on the degree of inhibition expected when the two are activated together. For example, the role of $\mathrm{G} \alpha_{\mathrm{q} / 11^{-}}$ GTP and G $\beta \gamma$ in VI modulation is not known. One may speculate that $\mathrm{G} \alpha_{\mathrm{q} / 11}-\mathrm{GTP}$ can bind to (or activate a secondary molecule that can bind to) the $\mathrm{G} \beta \gamma$-bound calcium channel. This interaction may simply render the inhibition of $\mathrm{G} \beta \gamma$ voltage independent by preventing $\mathrm{G} \beta \gamma$ release in response to strong depolarizations. On the contrary, this interaction may produce further inhibition unrelated to the VD mechanism beyond its requirement for $\mathrm{G} \beta \gamma$. The data in Figure 6 indicate that the prepulse inhibition produced by each pathway is similar (when at least some of the VD-modulated channels become VI modulated), but this information alone does not allow either possibility to be ruled out. Still, these data raise the question of whether other G $\alpha$-GTPs can induce effects similar to that of $\mathrm{G} \alpha_{\mathrm{q} / 11}-\mathrm{GTP}$, but with varying potencies. This possibility may explain why in some systems VD inhibition is completely reversed, or nearly so, by depolarizing voltage steps, whereas in others (where other forms of G $\alpha$-GTP may be involved) the facilitation is only partial (but see Jones and Elmslie, 1997; Delmas et al., 1998b).

To definitively confirm that the VI pathway of calcium current modulation required both $\mathrm{G} \alpha_{\mathrm{q} / 11}$-GTP and $\mathrm{G} \beta \gamma$, we attempted to overexpress a constitutively active $\mathrm{G} \alpha_{\mathrm{q}}\left(\mathrm{G} \alpha_{\mathrm{q}} \mathrm{Q} 209 \mathrm{~L}\right)$ (Qian et al., 1993) and introduce $\mathrm{G} \beta \gamma$ (for example by application of NE) to mimic VI inhibition. However, in attempting this experiment we encountered several problems that made interpretation difficult. First, cells expressing constitutively active $\mathrm{G} \alpha_{\mathrm{q}}$ exhibited greatly reduced calcium currents. Unfortunately, the remaining current possessed a strongly inactivating time course unlike that seen in control cells inhibited by oxo-M (Delmas et al., 1998a,b). This led to concerns that long-term exposure to constitutively active $\mathrm{G} \alpha_{\mathrm{q}}$ may induce changes in the cells (such as the initiation of the phospholipase $\mathrm{C}$ pathway and even possible activation of small G-protein pathways) unrelated to the pathways that we wished to study. These changes may not be observable in the short-term under patch-clamp conditions. Another concern was that the VI inhibitory pathway would be saturated by the presence of constitutively active $\mathrm{G} \alpha_{\mathrm{q}}$ and basally activated $\mathrm{G} \beta \gamma$.

In conclusion, we have confirmed that muscarinic calcium current inhibition in sympathetic neurons from the rat SCG possesses both a VD and a VI component. The VD pathway is PTX sensitive, mediated by $\mathrm{G} \beta \gamma$, and appears to be activated by $\mathrm{M}_{4}$ $\mathrm{mAchRs}$ because it is insensitive to the specific $\mathrm{M}_{1} \mathrm{mAchR}$ antagonist, $\mathrm{M}_{1}$-toxin. The VI pathway is PTX insensitive and is initiated by $M_{1}$ mAchRs. In addition, this VI pathway is sensitive to the presence of RGS2 and PLC $\beta$-ct, indicating that it requires $\mathrm{G} \alpha_{\mathrm{q} / 11^{-}}$ GTP. Finally, this pathway also appears to require activation of $\mathrm{G} \beta \gamma$, as is apparent by its sensitivity to MAS-GRK3 and $\mathrm{G} \alpha_{\mathrm{tr}}$. An apparently similar VI modulation initiated by $\mathrm{NK}_{1}$ activation was sensitive to buffering of $\mathrm{G} \beta \gamma$. Further studies are necessary to elucidate the details of the mechanism of VI inhibition in SCG neurons and to determine whether this mechanism is used in other systems.

\section{REFERENCES}

Bean BP (1989) Neurotransmitter inhibition of neuronal calcium currents by changes in channel voltage dependence. Nature 340:153-156.

Beech DJ, Bernheim L, Hille B (1992) Pertussis toxin and voltage dependence distinguish multiple pathways modulating calcium channels of rat sympathetic neurons. Neuron 8:97-106.

Beech DJ, Bernheim L, Mathie A, Hille B (1991) Intracellular $\mathrm{Ca}^{2+}$ buffers disrupt muscarinic suppression of $\mathrm{Ca}^{2+}$ current and $\mathrm{M}$ current in rat sympathetic neurons. Proc Natl Acad Sci USA 88:652-656.

Bernheim L, Beech DJ, Hille B (1991) A diffusible second messenger mediates one of the pathways coupling receptors to calcium channels in rat sympathetic neurons. Neuron 6:859-867.

Bernheim L, Mathie A, Hille B (1992) Characterization of muscarinic receptor subtypes inhibiting $\mathrm{Ca}^{2+}$ current and $\mathrm{M}$ current in rat sympathetic neurons. Proc Natl Acad Sci USA 89:9544-9548.

Delmas P, Abogadie FC, Dayrell M, Haley JE, Milligan G, Caulfield MP, Brown DA, Buckley NJ (1998a) G-proteins and G-protein subunits mediating cholinergic inhibition of N-Type calcium currents in sympathetic neurons. Eur J Neurosci 10:1654-1666.

Delmas P, Brown DA, Dayrell M, Abogadie FC, Caulfield MP, Buckley NJ (1998b) On the role of endogenous G-protein $\beta \gamma$ subunits in N-type $\mathrm{Ca}^{2+}$ current inhibition by neurotransmitters in rat sympathetic neurons. J Physiol (Lond) 506.2:319-329.

Delmas P, Abogadie FC, Milligan G, Buckley NJ, Brown DA (1999) $\beta \gamma$ dimers derived from $G_{0}$ and $G_{i_{2}}$ proteins contribute different components of adrenergic inhibition of $\mathrm{Ca}^{2+}$ channels in rat sympathetic neurones. J Physiol (Lond) 518.1:23-26.

DeWaard M, Liu H, Walker D, Scott VES, Gurnett CA, Campbell KP (1997) Direct binding of G-protein $\beta \gamma$ complex to voltage-dependent calcium channels. Nature 385:446-450.

Diverse-Pierluissi M, Remmers AE, Neubig RR, Dunlap K (1997) Novel form of crosstalk between G-protein and tyrosine kinase pathways. Proc Natl Acad Sci USA 94:5417-5421.

Elmslie KS, Zhou W, Jones SW (1990) LHRH and GTP- $\gamma$-S modify calcium current activation in bullfrog sympathetic neurons. Neuron 5:75-80.

Filippov AK, Webb TE, Barnard EA, Brown DA (1998) $\mathrm{P}_{2} \mathrm{Y}_{2}$ nucleotide receptors expressed heterologously in sympathetic neurons inhibit both N-type $\mathrm{Ca}^{2+}$ and M-type K ${ }^{+}$currents. J Neurosci 18:5170-5179.

Herlitze S, Garcia DE, Mackie K, Hille B, Scheuer T, Catterall W (1996) Modulation of $\mathrm{Ca}^{2+}$ channels by G-protein $\beta \gamma$ subunits. Nature 380:258-262.

Heximer SP, Watson N, Linder ME, Blumer KJ, Hepler JR (1997) RGS2/ GOS8 is a selective inhibitor of $\mathrm{G}_{\mathrm{q}} \alpha$ function. Proc Natl Acad Sci USA 94:14389-14393.

Hille B (1994) Modulation of ion channel function by G-protein coupled receptors. Trends Neurosci 17:531-535.

Ikeda SR (1997) Heterologous expression of receptors and signaling proteins in adult mammalian sympathetic neurons by microinjection. In: Methods in molecular biology (Challis RAJ, ed), pp 191-202. Totowa, NJ: Humana.

Ikeda SR (1996) Voltage-dependent modulation of N-type calcium channels by G-protein $\beta \gamma$ subunits. Nature 380:255-258.

Jones SW, Elmslie KS (1997) Transmitter modulation of neuronal calcium channels. J Membr Biol 155:1-10.

Kammermeier PJ, Ikeda SR (1999) Expression of RGS2 alters the coupling of metabotropic glutamate receptor 1 a (mGluR1a) to M-type $\mathrm{K}^{+}$ and N-type $\mathrm{Ca}^{2+}$ channels. Neuron 22:819-829.

Krause JE, Sachais BS, Blount P (1994) Tachykinin receptors. In: Handbook of receptors and channels (Peroutka SJ, ed), pp 277-298. Boca Raton, FL: CRC.

Lewis DL, Ikeda SR (1997) Inhibition of M-type $\mathrm{K}^{+}$and $\mathrm{N}$-type $\mathrm{Ca}^{2+}$ channels by the human gonadotropin-releasing-hormone receptor heterologously expressed in adult neurons. Neuroendocrinology 66:235-245.

Max SI, Liang JS, Potter LT (1993) Purification and properties of m1toxin, a specific antagonist of $\mathrm{m} 1$ muscarinic receptors. J Neurosci 13:4293-4300.

Page KM, Stephens GJ, Berrow NS, Dolphin AC (1997) The intracellular loop between domains I and II of the B-type calcium channel confers aspects of G-protein sensitivity to the E-type calcium channel. J Neurosci 14:1330-1338.

Qian N-X, Winitz S, Johnson GL (1993) Epitope-tagged $\mathrm{G}_{\mathrm{q}} \alpha$ subunits: expression of GTPase-deficient $\alpha$ subunits persistently stimulates 
phosphatidylinositol-specific phospholipase $\mathrm{C}$ but not mitogen-activated protein kinase activity regulated by the $\mathrm{M}_{1}$ muscarinic receptor. Proc Natl Acad Sci USA 90:4077-4081.

Schofield GG (1990) Norepinephrine blocks a calcium current of adult rat sympathetic neurons via an $\alpha_{2}$-adrenoceptor. Eur J Pharmacol 180:37-47.

Shapiro MS, Hille B (1993) Substance P and somatostatin inhibit calcium channels in rat sympathetic neurons via different $G$ protein pathways. Neuron 10:11-20.

Shapiro MS, Loose MD, Hamilton SE, Nathanson NM, Gomeza J, Wess J, Hille B (1999) Assignment of muscarinic receptor subtypes mediating G-protein modulation of $\mathrm{Ca}^{2+}$ channels by using knockout mice. Proc Natl Acad Sci USA 96:10899-10904.

Shapiro MS, Wollmuth LP, Hille B (1994) Angiotensin II inhibits calcium and $\mathrm{M}$ current channels in rat sympathetic neurons via $\mathrm{G}$ proteins. Neuron 12:1319-1329.

Wu D, Jiang H, Katz A, Simon MI (1993) Identificaion of critical regions on phospholipase C- $\beta 1$ required for activation by G-proteins. J Biol Chem 268:3704-3709.

Zamponi GW, Bourinet E, Nelson D, Nargeot J, Snutch TP (1997) Crosstalk between $\mathrm{G}$ proteins and protein kinase $\mathrm{C}$ mediated by the calcium channel $\alpha_{1}$ subunit. Nature 385:442-446.

Zhang JF, Ellinor PT, Aldrich RW, Tsien RW (1996) Multiple structural elements in voltage-dependent $\mathrm{Ca}^{2+}$ channels support their inhibition by G proteins. Neuron 17:991-1003.

Zhu Y, Ikeda SR (1994) Modulation of $\mathrm{Ca}^{2+}$-channel currents by protein kinase $\mathrm{C}$ in adult rat sympathetic neurons. J Neurophysiol 72: 1549-1560. 